\title{
Driving after a stroke: What helps Grandma drive safely?
}

Elizabeth Roaf, MD; and Janet Jankowiak, MD

Crashes involving elderly drivers hitting pedestrians are increasing at an alarming rate. With the graying of America, the impact of driving impairment is being reported more commonly. In the year 2000 (according to US Census data), people over the age of 65 equaled $13 \%$ of the United States population yet were involved in $18 \%$ of all traffic fatalities. Many medical conditions may lead to problems with driving, including the process of normal aging. These may include conditions that affect the brain and its connections, the heart, eyes, ears, muscles, and even bones. But what can be done to ensure that people with these conditions can drive safely?

New research reported in this issue of Neurology suggests that people who have had a recent stroke may benefit from special driving training that takes place in a car modified with a driving simulator. In this study by Akinwuntan et al., the authors used a full-sized Ford Fiesta car which remains stationary. The car was equipped with adaptive aids such as a left-sided accelerator pedal, right-sided indicator stick, as well as a steering wheel coupled to a simulator. The stimulator projected life-sized images generated by a computer that portrayed a driving scenario that lasted about 25 minutes. Akinwuntan et al. divided 83 patients who had had a stroke within the past 3 months into two groups for the study. ${ }^{1}$
In one group, there were 42 people who were chosen at random to use the driving simulator. The other group of 41 people, called the control group, received standardized training by performing drivingrelated thinking tasks such as finding a route on a road map. The goal of the study was to see if the specialized simulator-training program would improve driving performance and skills. Each potential driver spent 1 hour 3 days per week for 5 weeks either in the stationary car with steering wheel, signals, brakes, and a driving simulation program, or in the mental skills course. All the participants were younger than 75 years old, had a valid driver's license before their stroke, and had no prior history of problems with speech, understanding, or a seizure disorder. The size and location of each stroke was noted; the subjects were checked for visual problems and thinking functions such as attention to visual and tactile input after the stroke. Information about driving experience, average distance driven annually before the stroke, and educational level was collected on each person.

Each participant was tested before and after the driving training. It was found that the individuals with higher levels of education and smaller strokes tended to do better on overall driving performance. Those who received training in the car with driving simulation tended to do better on tasks practiced during the simulation than those who

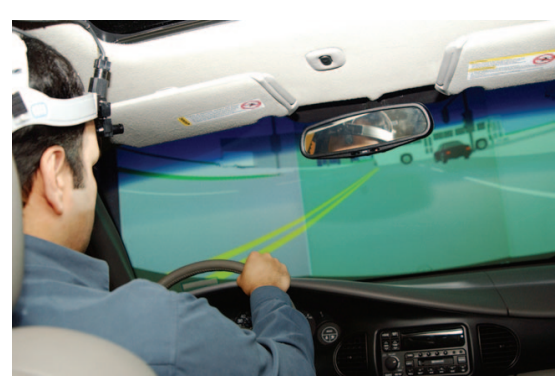

just participated in the thinking skills program. More of the people who used the simulated training did well on an actual on-road test taken about 3 months after the training than the control group who did the thinking skills training. The authors concluded that motor learning skills are better learned when they are learned in a similar situation to where they will be performed.

This study suggests that driving simulation in a modified vehicle may be helpful to certain individuals who have had a stroke and who want to resume driving. In this study, people with large strokes and those over 75 years old were excluded. However, the results suggest that simulated driving training may be a way to help improve driving performance. More research will be needed to see if this could help other potential drivers with other neurologic disorders, such as early dementia.

\section{Reference}

1. Akinwuntan AE, De Weerdt W, Feys H, et al. Effect of simulator training on driving after stroke: A randomized controlled trial. Neurology 2005;65:843-850. 


\section{What happens when you give up your driver's license?}

In the United States, public transportation systems between smaller towns and cities are relatively limited and driving is almost a necessity. The ability to drive has become a symbol of American independence. When there is a threat of losing the privilege to drive, older people or those with medical problems are faced with serious emotions. They may rightfully feel they are losing their independence and mobility in our society. If the retired driver does not have a strong social network of family or friends he or she may feel socially isolated. This may lead to feelings of depression, anger, and loss of control. In addition, necessary trips such as shopping at a grocery store or going to a doctor's office may become difficult.

\section{What medical conditions may impair driving?}

Each state has different restrictions on an individual's ability to drive given his or her medical condition. Many states require that drivers report certain medical conditions themselves. A few states require that physicians must report specific conditions. These may include loss of visual sharpness or peripheral vision, seizure disorders, problems with heart rhythm, severe breathing difficulties, and even severe arthritis. Medical problems that may interfere with an individual's ability to drive may be grouped into the following categories.

\section{Mental impairments}

These include any condition that affects an individual's ability to think, remember, or pay attention. Examples are strokes, dementias, loss of sleep, alcohol use, and use of various recreational drugs or medications (both prescribed and over the counter, for example sleeping pills or certain painkillers).

\section{Problems with sensation or movement}

These disorders include loss of feeling in the feet from diabetes or other nerve problems, loss of muscle power as a result of a stroke, or weakness with sciatica. Poor range of motion may also limit safe driving, especially in turning the head or ability to step on the brake quickly.

\section{Loss of consciousness}

This includes conditions where an individual faints, passes out, or is otherwise not aware of his or her surroundings. Examples include seizures, strokes, heart rhythm problems, low blood sugar, and alcoholic intoxication.

\section{Problems with vision}

This includes problems that affect the eye or eyes such as cataracts and macular degeneration, a common cause of partial blindness, as well as diabetic retinopathy, which affects the blood vessels of the eye. In addition, brain lesions in areas that involve the processing of visual information may affect vision. These include partial loss of the visual field from a stroke, tumor, or even a brain injury caused by trauma to the head.

\section{What should you do if you wonder whether your loved one is able to drive safely?} Some people with medical problems such as visual impairment, hearing loss, or slowed reflexes frequently limit their driving to local roads, shorter distances, daytime hours, and fair weather during non-rush hour traffic. Others with limited insight into their abilities may not restrict themselves, which puts themselves and others at risk.

Family members or caregivers may consider driving in a car behind an older driver or consider riding as a passenger with the driver from time to time. This will help the caregiver to watch the driving habits and skills of the individual.

Particularly important areas of concern are the following:

- Incorrectly making a left-hand turn

- Driving too fast or too slowly for the road conditions
- Making sudden turns

- Not using the turn indicator or forgetting to turn it off

- Getting lost or seeming disoriented

Unexplained dents on a car or recent fender benders may be a sign of frequent accidents or near misses. When there is any question about an individual's ability to drive, the best place to start is with the person's physician. The physician can make recommendations about specialists to see and treatment that may help the driver resume or continue driving.

As discussed in the article by Akinwuntan et al., specialized driving training using simulated driving scenarios in a stationary, specially equipped vehicle may be a way to improve driving performance. Although this study focused on individuals who had had strokes, similar training may be helpful to people with other neurologic impairments such as brain injury, mild dementia, or Parkinson disease, or perhaps even healthy elderly drivers.

\section{For more information}

Massachusetts Medical Society's guidebook "Medical perspectives on impaired driving"

www.massmed.org

American Medical Association's guidebook "Assessing and counseling older drivers"

www.ama-assn.org/go/olderdrivers

National Highway Transportation Safety

Administration

www.nhtsa.dot.gov

AARP 55 Alive Mature Driving

Program

www.aarp.org/55alive

AAA Safe Driving for Mature Operators Program

www.aaa.com 


\title{
Neurology
}

\author{
Driving after a stroke: What helps Grandma drive safely? \\ Elizabeth Roaf and Janet Jankowiak \\ Neurology 2005;65;E13-E14 \\ DOI 10.1212/01.wnl.0000180597.35193.c6
}

This information is current as of September 26, 2005

\section{Updated Information \&} Services

References

Citations

Permissions \& Licensing

Reprints including high resolution figures, can be found at: http://n.neurology.org/content/65/6/E13.full

This article cites 1 articles, 1 of which you can access for free at: http://n.neurology.org/content/65/6/E13.full\#ref-list-1

This article has been cited by 1 HighWire-hosted articles: http://n.neurology.org/content/65/6/E13.full\#\#otherarticles

Information about reproducing this article in parts (figures,tables) or in its entirety can be found online at:

http://www.neurology.org/about/about_the_journal\#permissions

Information about ordering reprints can be found online:

http://n.neurology.org/subscribers/advertise

Neurology ${ }^{\circledR}$ is the official journal of the American Academy of Neurology. Published continuously since 1951, it is now a weekly with 48 issues per year. Copyright . All rights reserved. Print ISSN: 0028-3878. Online ISSN: 1526-632X.

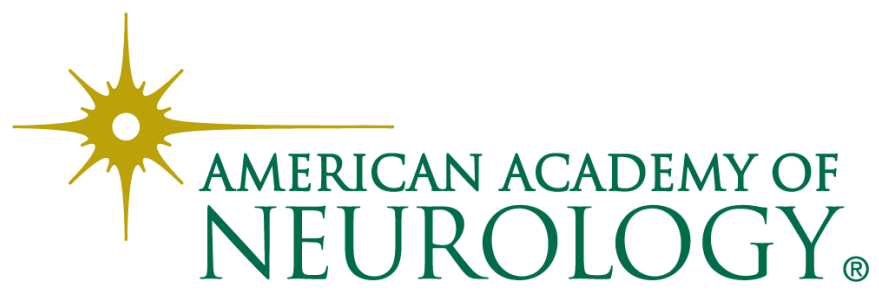

